\title{
REFLEXÕES ACERCA DO ESTÁGIO CURRICULAR NA FORMAC̦ÃO DO PROFESSOR LICENCIADO EM TEATRO
}

José Simões de Almeida Junior*

RESUMO: A partir de um breve panorama histórico, busca-se apontar enfrentamentos e dificuldades políticas e culturais em torno da inserção do ensino de teatro, como campo de conhecimento no currículo da Educação Básica. Toma-se como objeto para esta discussão o estágio supervisionado obrigatório e o seu papel na formação do futuro docente. Nesse contexto, os relatos dos alunos estagiários buscam somar à reflexão do estágio curricular obrigatório como espaço de formação do ofício da docência, do diálogo entre os imaginários teatrais vivenciados na formação artística ao longo da formação e aquele realizado pelas práticas escolarizadas e na visibilidade do teatro no território escolar.

Palavras-chave: Estágio Curricular; Ensino de Teatro; História do Teatro Educação; Teatro na Escola.

\section{REFLECTIONS ON CURRICULAR INTERNSHIP IN THE TRAINING OF LICENSED DRAMA TEACHERS}

ABSTRACT: This article describes a brief history of Drama in the curriculum of Basic Education and its development to date. It discusses the difficulties and issues concerning the insertion of a Drama course as a field of knowledge in Basic Education. Internship requirement and its role in shaping future teachers are the main discussion topics. The purpose was to reflect on the role of drama as a space for dialogue between the ideal drama teaching training practice and the real artistic experience in the classroom.

Keywords: Curricular Internship; Drama Teaching; History of Drama Education; Drama in school.

\footnotetext{
*Doutor em Lingüística pela Universidade Estadual de Campinas (UNICAMP) e Professor Adjunto I da Universidade Federal da Fronteira Sul (UFFS). E-mail: p.simoes@uol.com.br
} 
A experiência no estágio curricular supervisionado em teatro se constitui num importante espaço pedagógico no percurso formativo dos licenciados em teatro. Pois a atividade se vincula à presença do futuro professor na sala de aula. Nela se instaura a experiência docente, capaz de motivar um conjunto de discussões e reflexões acerca da práxis do ensino de teatro, no território escolar.

Deseja-se, neste artigo, apontar enfrentamentos e dificuldades que envolvem o ensino de teatro na escola, tomando como objeto de reflexão a formação do docente a partir das atividades desenvolvidas no estágio curricular supervisionado obrigatório. Para tanto, faz-se necessária à revisão do panorama histórico da inserção na escola brasileira do ensino de teatro, identificando os ganhos e as perdas que ocorreram ao longo desta temporalidade e seus impactos nas políticas educacionais, voltadas ao ensino da Arte, que interferira diretamente no trabalho docente, na sala de aula.

Busca-se, ainda, valorizar o estágio curricular como o espaço do aprendizado do ofício da docência, da escuta e da emancipação do sujeito, na formação do futuro professor. Nesse contexto, cabe propor que nos procedimentos pedagógicos do estágio se integre um plano de intervenção teatral, com o objetivo de ampliar a visibilidade do teatro (como atividade cultural) na paisagem do território escolar. Uma vez que nele poderão ser propostas e incorporadas estratégias artístico-pedagógicas fora do ambiente da sala de aula (com a colaboração do professor supervisor de campo), que resultem no contato dos alunos e professores com pequenas cenas, ida ao teatro, oficinas, etc. Enfim, atividades teatrais as quais possam envolver a escola, de tal modo a tornar a prática cultural do teatro concreta e visível no território escolar.

Koudela afirma que o ensino de Arte - no qual o teatro se insere - ao longo da história da educação, muitas vezes, careceu “[...] de caracterização de conteúdos específicos, substituídos na maioria das vezes por objetivos educacionais amplos, que poderiam ser atingidos por qualquer outro campo de estudo [...]" (1984, p. 22). Esta falta de especificidade, em relação aos conteúdos da área de conhecimento, resultou numa série de confusões e conflitos. O que nos leva a enfatizar, no processo de formação dos professores, a necessidade de contínuas discussões acerca da epistemologia e metodologias do ensino de teatro na escola, não somente para romper com a lógica das 
generalizações, mas para construir a identidade e o reconhecimento da pedagogia do teatro ${ }^{1}$, no âmbito do currículo escolar.

Maria Lucia Pupo (2005, p. 218) afirma que

O avanço da pesquisa no campo da pedagogia do teatro depende, dentre outros fatores, da clareza dos conceitos que a configuram. A reflexão sobre a natureza, as finalidades e os procedimentos da aprendizagem teatral é atravessada, como sabemos, pelas interrogações próprias dos processos educacionais e pelas surpresas inerentes à conquista do conhecimento nas artes [...].

É, portanto, no campo movediço e permeado de interrogações que se insere o estágio supervisionado na formação dos futuros professores. No contato dos estagiários com a rotina e a realidade da sala de aula, emergem questionamentos e reflexões acerca do processo ensino/aprendizagem na escola. São frequentes: por onde começar? O que fazer? Como fazer? Onde está o teatro na escola?

As perguntas são aparentemente simples. As respostas, nem tanto. Nesse sentido, para avançarmos na discussão e fundamentar as possíveis respostas é necessário situar o ensino de teatro na Educação Básica. Entre os atravessamentos presentes na aprendizagem teatral, produzidos ao longo dos processos e políticas educacionais, temos o ensino de teatro alocado - como conteúdo - no interior da disciplina Arte $^{2}$.

O teatro, portanto, encontra-se não visivel como disciplina no currículo da Educação Básica. Diante desta situação a atuação do professor na sala de aula é muito importante, considerando que será ele o responsável pela abordagem do conteúdo, refletindo, entre outras coisas, na visibilidade e valorização, de uma ou outra, prática artística no dia a dia dos alunos.

As propostas curriculares vigentes relacionadas à formação artística na Educação Básica variam de estado para estado na federação e, na sua maioria, são de viés generalista. Permanecem alicerçadas de um modo ou de outro na leitura e proposta dos PCNs. Nesse contexto, escondem um conjunto de ao menos quatro dificuldades para a sua execução. A primeira delas, que salta aos olhos, relaciona-se à formação do docente para ministrar estes conteúdos artísticos na disciplina Arte. Tomando o exemplo do Estado de São Paulo ${ }^{3}$, observamos que não há, no momento, cursos de graduação específicos na formação em Arte, cujo projeto político pedagógico consiga 
capacitar plenamente os futuros professores, em relação aos conteúdos demandados no referido documento.

A segunda dificuldade seria a compreensão de quais são os objetivos específicos do ensino de Arte na Educação Básica para cada linguagem. A terceira relaciona-se à distribuição ao longo da formação do aluno, na matriz curricular, da disciplina Arte, para que os objetivos propostos sejam atendidos. A quarta dificuldade são as condições materiais e espaciais para a realização adequada do ensino de Arte na escola. Não se encerram por aqui a lista de dificuldades. Nem é este o objetivo do texto. Serve, todavia, para contextualizarmos a situação caótica enfrentada pelo futuro professor da disciplina Arte, ao ingressar na Educação Básica.

A legislação federal vigente permite apenas a abertura de cursos de formação de professores em linguagens específicas - teatro, música, dança e artes visuais. Isso significa que os professores licenciados, ao ingressarem na docência em Arte, conhecem uma das linguagens. Não significa, portanto, que os profissionais licenciados numa dada linguagem artística não transitem pelas outras artes. O hibridismo e a ausência de fronteiras entre os campos artísticos são recorrentes nas artes contemporâneas na atualidade. Todavia, o foco formativo na graduação do licenciado será apenas numa das linguagens.

Assim, o futuro professor licenciado em teatro, nesse contexto pouco claro, terá como opção, ao trabalhar na disciplina Arte, desenvolver atividades em sala de aula (para cumprir as diretrizes propostas) como mediador ${ }^{4}$ de todas as linguagens artísticas (teatro, artes visuais, música e dança). Ou então, considerar o teatro como eixo central da discussão e formação do aluno na sala de aula e, a partir dele, estabelecer a mediação e dialogar com as outras linguagens artísticas. O conhecimento em teatro seria, portanto, o referencial e a premissa para a inserção da discussão da Arte na educação.

Não se pretende encerrar a discussão e nem avançar noutras possibilidades metodológicas para o ensino da Arte. Os estudos acerca dos processos de mediação se desdobram e avançam por caminhos, por vezes, labirínticos e merecem outra abordagem e discussão aprofundada. Cabe no contexto deste artigo apontar que tanto uma como outra possibilidade encontra-se diretamente relacionada à formação do futuro licenciado e aos atravessamentos políticos e culturais envolvendo a inserção do ensino de teatro na escola atual. 
Assim, antes de avançarmos a discussão, é necessário olharmos o percurso histórico da inserção do teatro na escola, no sentido de buscar pistas que nos levem a compreender esta trajetória e este lugar que hoje o teatro ocupa na escola.

\section{COINCIDÊNCIA HISTÓRICA: A CRIAC̣ÃO DA ESCOLA NO BRASIL E A INSERĈ̣̃O DO TEATRO NA EDUCAÇ̃̃O}

A escola no Brasil se estabelece a partir da chegada dos jesuítas e da colonização portuguesa. Neste contexto, observamos a coincidência histórica entre a criação da escola no Brasil e a inserção do ensino de teatro, como atividade curricular na Educação Básica.

Os jesuítas, responsáveis pela organização inicial da escola no Brasil, trouxeram consigo o método pedagógico no qual o teatro, de modo institucionalizado, era utilizado como estratégia no processo formativo ${ }^{5}$ dos alunos.

Segundo Ferreira Junior e Bittar (2004, p. 179, grifo nosso),

[...] de acordo com fontes primárias, como as cartas dos primeiros jesuítas, viajantes e cronistas do Brasil colonial, o teatro foi introduzido concomitantemente à ocupação territorial patrocinada pela Coroa Portuguesa. Portanto, tal como na atividade educacional, os jesuítas foram pioneiros e exerceram o monopólio no âmbito das artes cênicas representadas nas terras brasílicas, pois somente na segunda metade do século XVII surgiu um cultor de teatro fora da Companhia. .

É significativa, no caso do ensino do teatro na escola, esta coincidência inicial, pois se constitui no marco zero do ensino de teatro (institucionalizado na escola) no País.

A relação entre educação e teatro proposta pelos jesuítas no Brasil tinha, ao mesmo tempo, o objetivo da catequese e da formação do homem, assim como se propunha a ser o veículo de propagação da língua e do próprio fazer teatral, como elementos integrantes do exercício necessário para a consciência do outro ${ }^{6}$.

O teatro não era somente realizado no dia a dia da sala de aula, mas nos espaços comuns escolares e, também, ultrapassava os muros da escola se inserindo na comunidade. 
Segundo Serafim Leite, as encenações transcorriam em duas instâncias: nas aldeias e nos colégios, sendo que nestes com estilo "mais escolástico e grave" (Leite, 1938, p. 599). Nas aldeias, representavam-se autos, termo originado do latim "actus" porque, possivelmente, a representação durava apenas um ato. Já nos colégios, além de autos, havia comédias e tragédias. Apesar dessa distinção, o objetivo era sempre moral. Quanto aos cenários, variavam entre a sala grande dos colégios, a praça pública e as aldeias; sendo estas últimas as preferidas dos jesuítas.

Na pedagogia proposta por Ignácio Loyola, a base da formação do indivíduo se constituía pela atividade do exercício espiritual. Isto significa, em poucas palavras, que a formação no processo ensino/aprendizagem estava vinculada à capacidade do indivíduo em conseguir administrar as relações entre a interioridade exterioridade do eu. Nesse contexto, Loyola considerava o teatro como um dos procedimentos disciplinares que possibilitaria tal exercício.

$\mathrm{O}$ ensino de teatro não somente atenderia à aquisição de uma dada informação, por exemplo, uma ação física, mas também possibilitaria a compreensão interna dessa ação. Isto é, na prática teatral proposta por Loyola, a ação física (externo) não estaria dissociada da interioridade, portanto, estaria articulada a uma intencionalidade e a sua consciência. (MEIRIEU, 2002, p 34). O exercício proposto por Loyola pode nos remeter (guardadas as devidas temporalidades) ao método das ações físicas proposto por Stanislavski no teatro ${ }^{7}$.

Se historicamente temos a presença do teatro na educação ${ }^{8}$ desde o princípio do processo de desenvolvimento da escola brasileira, por que não temos na atualidade o pleno desenvolvimento do ensino de teatro na Educação Básica?

A ruptura nesse processo se deu por vários motivos e contextos históricos. O primeiro deles foi a expulsão dos jesuítas do Brasil, seguido da reforma desenhada pelo Marquês de Pombal, combatente ferrenho das propostas jesuíticas para a educação.

Ana Mae (1978, p. 22) afirma que:

[...] em Portugal, o Marquês de Pombal (responsável pela perseguição aos jesuítas) planejou e fez executar uma reforma educacional que se concentrou na exploração dos aspectos educacionais nos quais fora omissa a ação jesuítica e numa renovação metodológica que abrangia as Ciências, as Artes Manuais e a Técnica. 
A reforma pombalina significou retirar da centralidade as lógicas do currículo proposto pelos jesuítas. Portanto, desde a saída dos jesuítas até a chegada da Coroa ao Brasil, o teatro foi aos poucos perdendo o seu espaço no currículo escolar.

É certo que a vinda da família real para o Brasil, em 1808, trouxe consigo melhorias e investimentos para a atividade artística teatral. Juntamente com a transferência da Coroa Portuguesa, houve um aumento na vinda de companhias de teatro do exterior, o que, por um lado, estimulava a criação de outras possibilidades de contato com técnicas artísticas e teatrais no País, por outro, fomentava a formação de mão de obra no interior dessas companhias que aos poucos se estruturavam no País.

Tal interferência, contudo, não impediu o definhar do teatro como prática pedagógica regular no interior da escola, que passou a ocupar outros espaços (tais como os grêmios, festas comemorativas, etc.) na dinâmica escolar.

\section{O DIFÍCIL RETORNO DO TEATRO AO CURRÍCULO DA ESCOLA}

Depois da reforma pombalina e tudo o mais que se sucedeu na história da Educação Brasileira, o teatro ainda continuou presente nalgumas escolas como atividade extracurricular. A prática pedagógica deixada pelos jesuítas não foi facilmente apagada pelas reformas e sobreviveu nas bordas do território escolar, principalmente, fora da sala de aula, mas, ainda, no interior das escolas nas festas escolares, nos grêmios, etc.

Deste período até o século XIX, as informações são lacunares acerca do ensino de teatro na escola da educação básica. Somente a partir do século XX, com o movimento escolanovista, retoma-se a discussão do ensino de teatro como conbecimento específico na escola. Segundo Arão Santana (2002, p. 249)

As primeiras práticas de teatro-educação surgiram junto às escolinhas de arte de Augusto Rodrigues, disseminando-se aos poucos em colégios experimentais, escolas de magistério etc. Entretanto, como não havia tradição em termos de ensino da linguagem teatral - seja na educação básica ou profissionalizante -, ocorreu a difusão massiva do espontaneísmo, quando não o papel de atividade coadjuvante de outras matérias do currículo. 
O teatro na escola percorreu um caminho sinuoso e de emaranhados históricos, Santana (2002, p. 250, grifo nosso) descreve:

[...] no Brasil, a arte penetrava na escola através de atividades ligadas ao desenho geométrico, trabalhos manuais e canto orfeônico, sendo que o teatro e a dança tinham importância menor. Com a promulgação da Lei de Diretrizes e Bases (1961), inseriram-se no currículo da escola fundamental as práticas educativas, nas quais constava a arte dramática [...].

Desde os anos 60 até os nossos dias, os avanços e retrocessos na relação teatro e escola são sentidos pelos alunos e alunas (futuros professores) que optam pela licenciatura em Teatro?

Entre as questões inerentes à condição laboral da docência, ao modus operandi da legislação, à estrutura organizacional da atual da Educação Brasileira, já rapidamente descritas, temos as peculiaridades e especificidades envolvendo a prática da inserção do Teatro, como disciplina e campo de conhecimento específico, no currículo da Educação Básica nas últimas décadas.

Uma das questões específicas enfrentadas pelo professor de teatro trata-se da identidade da profissão e do profissional docente, no ambiente de trabalho. Isto é, a divergência entre a denominação da habilitação universitária - professor licenciado em Teatro - e a disciplina na qual irá trabalhar: Arte (segundo a legislação educacional LDB no 9.394/96). Desse modo, o futuro docente trabalhará numa disciplina que, na maioria das escolas, não se denomina Teatro, mas, sim, Arte ${ }^{10}$. Na qual o teatro poderá vir a ser um dos conteúdos ${ }^{11}$ a ser desenvolvido ao longo da formação básica do aluno. Não obstante os pequenos avanços na legislação na garantia do ensino (efetivo) de Teatro nas escolas, na maioria delas, a lógica polivalente ainda persiste impregnada no dia a dia do professor. As Secretarias Estaduais e Municipais de Educação, por meio de suas diretrizes, indicam que o conteúdo da disciplina Arte deve ser constituído por uma parte de dança, teatro, artes visuais, música. Como resultado, temos: produção didática sem reflexão, sem profundidade, em compartimentos que não dialogam. O resultado na maioria das vezes é desolador.

Os futuros professores aptos para a disciplina Arte não recebem nos cursos de graduação este tipo de formação plural. Estudam e aprofundam os conhecimentos na linguagem escolhida: Teatro, Dança, Música e Artes 
Visuais. Portanto, não há profissionais (em formação) capazes de atender às demandas imaginadas pelas secretarias de educação.

\section{OS FUTUROS PROFESSORES DE ENSINO DE TEATRO NO CONTEXTO DA DISCIPLINA ARTE}

É possível observar que o jovem licenciado em Teatro frequentemente não resiste e permite a redução do ensino de teatro a ferramentas de apoio para as outras disciplinas do currículo; ou ocupa-se da diversão na escola, em práticas fundadas nas dinâmicas de lazer. Significa, pois, que o jovem profissional não consegue espaço na disciplina Arte para articular, desenvolver estratégias e ensinar o teatro como conhecimento específico (que é a sua área de formação).

Estas dificuldades não somente são o resultado de um conjunto de motivações já apontadas anteriormente, mas, também, do descompasso entre formação acadêmica proposta aos licenciados em teatro e o mercado profissional (SANTANA, 2000). Nalguns casos, temos a falta de especificidade da licenciatura em teatro como principal fator dessa lacuna. Muitos desses problemas já são velhos conhecidos, como aponta Arão Santana (2000, p. 10), encontram-se como formas cristalizadas e naturalizadas no processo educacional, tal como: "[...] a dicotomia entre licenciatura e bacharelado; a formação teórica versus prática [...]”.

Outra questão, não menos importante, encontra-se vinculada às relações e às significações complexas existentes entre o teatro, a cultura e a sociedade que interferem indiretamente na prática e na inserção do ensino de teatro na escola. É sabido que o discurso acerca da relevância da cultura na contemporaneidade passou a permear às várias instâncias da sociedade, a ponto de se tornar imperativo e emergente (YÚDICE, 2004). Do mesmo modo, a noção de ambiente criativo se naturalizou, como resultado do envolvimento e da realização de atividades artísticas e tecnológicas em espaços específicos na cidade, tal como um espaço capaz de gerar inovação (CASTELLS, 2000). Segue, ainda, no bojo das discussões fundadas na centralidade da cultura o surgimento de outros neologismos e conceitos como as cidades criativas, economias criativas, indústrias criativas, etc.; refletindo o envolvimento e a importância da produção simbólica artística na sociedade atual. 
Imaginava-se, nesse contexto, que o teatro também pudesse vir a ter uma posição de valorização na cultura. Todavia, na relação entre teatro e escola, estas discussões não seguiram tal movimento. Isso porque o teatro há muito perdeu o seu espaço central na cultura das cidades (ABIRACHED, 2008, p. 25). Passando a ocupar espaços periféricos na cultura nos contextos econômicos pós-industriais e, também, do imaginário social. Esta perda de centralidade e de hegemonia na atividade cultural para outras formas e manifestações culturais (por exemplo: cinema, shows musicais, etc.) refletiu na visibilidade, percepção e no senso comum do papel do teatro na sociedade pelos sujeitos da escola.

Nesse contexto, se observa que as Artes e o teatro raramente são prioridade para as administrações dos governos municipais, estaduais e federal do Brasil (BOTELHO, 2002; CALABRE, 2005); como, também, não o são para a economia. Desse modo, não é incomum, no dia a dia da escola, se escutar de um grande grupo de famílias, que prefiram que seus filhos optem por profissões reconhecidas como médicos, engenheiros, mas não artistas.

Diante da percepção de falta de importância da arte na sociedade, fica fácil compreender, por exemplo, a ausência de investimentos nas estruturas necessárias para o exercício da atividade teatral ou na compra de matérias pedagógicos para o ensino de teatro. É notória a falta de condições espaciais ${ }^{12}$ e logísticas para o teatro acontecer na escola.

O ensino de teatro na escola requer uma espacialidade própria. Sem um espaço adequado, os professores são obrigados a constantes processos de adaptação, na busca de soluções possivieis e improvisadas para o exercício da profissão. Acentuando a precariedade e os desafios na sala de aula, no âmbito da Educação Básica.

O desejo é que o ensino de teatro na escola deixe de ser exceção e passe a ser uma atividade cotidiana como outra qualquer, integrada, sem regalias ou privilégios. Somente com os mesmos direitos e deveres, do qual todo aluno ou aluna poderia (e deveria) usufruir, independente de condição social, classe, gênero e cor ou da boa vontade de um professor ou professora, que, por ventura, conseguiu ultrapassar os obstáculos e realizou o teatro na escola.

O ensino de teatro não pode se estabelecer na escola a partir da lógica do discurso das boas intenções (e sacrifícios) de alguns docentes. Ele 
deve ter o seu espaço garantido e as condições necessárias de realização asseguradas.

A solução e o enfrentamento, para estes problemas e outros, não passam somente pela atuação do docente na sala de aula, mas, também, pela atuação política dos professores de Teatro dentro e fora da escola. $\mathrm{O}$ processo de valorização docente envolve a organização política da categoria dos professores de teatro.

Assim, é necessário tornar visiveis não somente estas questões políticas e educacionais que se sucedem ao longo da formação do futuro professor, mas também as questões que envolvem o lugar ocupado hoje pelo ensino de teatro na escola. Isto é, o próprio ensino de teatro como atividade artística e cultural que dialoga com a cidade na escola (e não separado dela).

Nesse contexto, busca-se fomentar, no estágio supervisionado obrigatório, além das relações ensino/aprendizagem formais associadas à epistemologia e práticas do ensino de teatro, estabelecer, a partir dele, espaços de ação cultural, nos quais se produzam planos de ação (e possíveis intervenções teatrais) que ultrapassem a sala de aula e se conectem com a produção teatral local. Ações estas responsáveis pela visibilidade do imaginário teatral na cidade e no território escolar.

\section{RELATO DO ESTÁGIO CURRICULAR: ESPAC̣OS DE INTERLOCUCְÃO ENTRE A SALA DE AULA E O ENSINO DE TEATRO}

As situações expostas ao longo do texto reinteram a importância na trajetória do licenciando em teatro, no processo de ensino/aprendizagem na Universidade, o contato com a prática e o ambiente escolar. Nesse contexto, um dos momentos de interlocução com a realidade educacional, especificamente voltado ao trabalho do professor em sala de aula, ocorre no estágio curricular obrigatório.

No meu dia a dia como professor na UFMG da disciplina Prática de Estágio Supervisionado III e IV, é possível distinguir (de modo geral) a presença de dois grupos de alunos, divididos de acordo com seus interesses a cada semestre. Um grupo de alunos que não tem a escolha da profissão docente como primeira opção de trabalho. São alunos que optam pela licenciatura, conforme seus depoimentos em sala de aula, como uma forma 
de certificação extra para enfrentar o mercado de trabalho, caso não deem certo como artistas. Outro grupo é de alunos que desejam de fato ser professores de teatro (ou ao menos não têm dúvidas em relação a esta opção).

Nossa experiência tem demonstrado, na sala de aula, que ambos os grupos de alunos iniciam as atividades com muitos discursos prontos em relação à escola: violência escolar, o desprestígio da profissão, baixos salários, entre outros.

À medida que a disciplina avança e o estágio se instaura, nas rodas de discussão durante as aulas, as preocupações e os discursos se alteram. A opção ou não pela profissão docente deixa de ser o elemento determinante para o envolvimento ou não dos alunos (isso não significa que ele desapareça). Talvez motivado pelo engajamento na disciplina. Mas, não sei ao certo.

O grupo dos alunos que desde o início se mostra vinculado à docência, geralmente, é aquele que traz as questões enfáticas acerca da formação do professor de teatro e, também, em relação ao curso de graduação. Queixa-se da ausência de disciplinas práticas vinculadas especificamente ao ensino de teatro na educação ao longo da formação do licenciado. Observando atentamente a esta demanda específica dos alunos, observei que não se trata necessariamente da ausência de disciplinas práticas ao longo do curso, mas do modo como são encaminhadas as discussões em relação aos objetivos esperados pelos alunos da licenciatura. De acordo com o relato dos alunos, são poucos os professores das disciplinas práticas, tais como improvisação, direção, entre outras, que expressam claramente o vínculo de uma dada técnica teatral com a educação. Isto é, o modo como aquela atividade artística (que está sendo vivenciada pelo licenciado) poderá se realizar na sala de aula, seus objetivos pedagógicos, etc., tanto no âmbito da educação formal como não formal. A situação enfrentada nesta relação ensino/aprendizagem considera que cabe ao aluno a responsabilidade de organizar tais conhecimentos e o desenvolvimento da prática pedagógica, para os seus futuros alunos - adolescentes e jovens - na escola.

Os futuros professores reclamam, ainda, no contexto educacional, do excesso de discursos. Nesse sentido Nóvoa (2009, p. 205) nos alerta

[...] a educação vive um tempo de grandes incertezas e de muitas perplexidades. Sentimos a necessidade da mudança, mas nem sempre conseguimos definir-lhe o rumo. Há um excesso de discursos, redundantes e repetitivos, que se traduz numa pobreza de práticas [...]. 
Sabemos que a prática docente não é fácil como se imagina ou se faz crer. Saber um conteúdo ou conhecer uma técnica não faz necessariamente de ninguém um professor. Não basta ao aluno se imaginar estar à frente de uma sala e diante deles falar ou escrever sobre algo acerca do que deve ser aprendido para se constituir docente. Tais premissas apenas reforçam uma pretensa falta de especificidade da docência e terminam se constituindo num dos elementos que favorecem a desvalorização da própria profissão docente.

É importante considerar quais são os elementos formativos, para além da discussão da imagem do professor para si e para outro social, necessários para se constituir a identidade profissional docente. Apontar com clareza as exigências profissionais didático-pedagógicas para o exercício da profissão do professor de teatro. Sabemos que na atualidade são muitas (gestão, planejar, comunicar, etc.) e se encontram em constante mobilidade.

Todavia, uma das necessidades imperiosas na formação do ofício da docência é a presença. Isto é, a necessidade de se estar na sala de aula, praticar e exercitar a docência. A experiência na e da sala de aula são determinantes na formação do futuro professor.

Todo ofício requer um lugar, no caso, a sala de aula. É fundamental conhecer espacial e socialmente a sala de aula. Observar as suas características acústicas, conhecer para onde se abrem as janelas e as possibilidades de alterar a distribuição dos alunos naquele local. Do mesmo modo, conhecer que são os sujeitos que vivem e usam o lugar. Pois nesse espaço se constituirá a prática da saber-ser e do saber-fazer que permitirá a identidade do futuro professor com aqueles que fazem parte do mesmo ofício na escola.

[...] a realização de um ofício no interior de uma dada oficina cria, dentre outras coisas, uma identidade entre os indivíduos e os objetos que estes manipulam, as ferramentas que manuseiam, os processos com os quais interagem. E ainda mais, cria uma identidade entre os indivíduos que são parceiros de rituais comuns, realizadores de um dado ofício e situados no ambiente da mesma oficina [...] (SOUSA NETO, 2005, p. 250).

Assim, o estágio é este espaço privilegiado na formação do estudante. Segundo o Art. 13 da resolução $\mathrm{CNE} / \mathrm{CP}$ :

Em tempo e espaço curricular específico, a coordenação da dimensão prática transcenderá o estágio e terá como finalidade promover a articulação das diferentes práticas, numa perspectiva interdisciplinar [...] (CONSELHO NACIONAL DE EDUCAÇÃ̃O, 2002). 
O estágio curricular deve ultrapassar a noção de aplicaşão de um conjunto de técnicas específicas do conhecimento teatral. Sendo o espaço para a imersão do aluno no ambiente escolar, na profissão docente, na prática pedagógica e seus rituais.

Nessa perspectiva da ação pedagógica de inserção no ofício da docência, observamos que a maioria dos relatos dos alunos (logo no início das supervisões do estágio) trata da escola como um uma entidade única, desprovida de singularidades. Repetem em coro: a escola é violenta; a escola é hostil ao ensino das artes, etc. Os temas sociais ganham relevância e eles se perguntam: o que eu sei acerca do papel da juventude na escola? Das relações familiares? Da violência escolar à indisciplina? Dos processos de cognição? O que sabemos acerca do ensinar? Que professores são esse na sala de aula?

Para exemplificar destaco o fragmento do relato escrito de uma aluna do estágio supervisionado ${ }^{13}$ após um dia de experiência na sala de aula:

[...] também essa professora não dá conta de lidar com a indisciplina. Briga muito e o tempo todo fala que não dá conta com os alunos e que vai chamar os pais ou alguém que tem mais autoridade que ela na escola para resolver a situação. Isso é muito recorrente com os outros dois professores também. Posso ser inocente na minha fala, mas será que eles não percebem que gritar, xingar, colocar de castigo não funciona? Os pais desses alunos provavelmente fazem isso e eles já estão acostumados. Não sei como eu faria, mas essa forma que buscam a disciplina não vigora. (aluna I).

A realidade apresentada no relato não nos possibilita uma resposta simples. A aluna não se identifica com a professora. Nem com as posturas da referida professora. Estes e outros relatos semelhantes criam, portanto, uma identidade negativa da profissão.

Segundo Sousa Neto (2005, p. 257):

Essa postura de desidentificação e identidade negativa gera um enorme enfraquecimento da comunidade profissional e, ao mesmo tempo, compromete sobremodo o exercício coletivo da profissão e suas mais justas reivindicações. Em princípio porque só defendemos aquilo com que nos identificamos de maneira positiva. Depois porque o elemento de coesão identitário muitas vezes utilizado para soldar ações comuns nada tem a ver com a profissão, já que os baixos salários não são privilégio apenas dos que exercem o ofício de professor [...]. 
A complexidade da iniciação à docência passa, antes mesmo de se buscar possíveis respostas e reflexões acerca das situações colocadas pelos alunos, no seu dia a dia, pela discussão da identidade do ofício da profissão docente.

São comuns nas rodas de conversa os alunos "lembrarem" de uma "escola melhor" do que aquela em que agora vivem a experiência docente. Portanto, há esperança e desejo de mudança.

Tardif (2002, p. 23) nos aponta:

Até agora, a formação para o magistério esteve dominada sobretudo pelos conhecimentos disciplinares, conhecimentos esses produzidos geralmente numa redoma de vidro, sem nenhuma conexão com a ação profissional, devendo, em seguida, serem aplicados na prática por meio de estágios ou de outros atividades do gênero. Essa visão disciplinar e aplicacionista da formação profissional não tem assim sentido hoje em dia, não somente no campo do ensino, mas também nos outros setores profissionais [...].

É importante que o estágio não se estruture na lógica da aplicação. Deve-se propor o estágio como um lócus de convergência e diálogo entre saberes, crenças e experiências de cada um dos participantes, futuros professores - espaço da emancipação. Não é simples. A lógica da aplicação e do como-se-faz encontra-se presente. Expressam (e desejam) a necessidade da sensação de segurança (em relação à prática docente) na sala de aula.

A orientação durante o estágio busca, antes de propor soluções e normatizar procedimentos, compartilhar as informações acerca das dificuldades enfrentadas pelos futuros professores na sala de aula, no sentido de trocar e tornar visível a experiência do outro. Para que os futuros professores possam se inserir na comunidade escolar como tradutores, narradores, observadores, sonhadores, intérpretes ativos da docência e dotados de competências técnicas da arte teatral em diálogo com o mundo da arte. Pois para Milton Santos "é o sonho que obriga o homem a pensar".

Nesse contexto, considera-se a supervisão do estágio fundamental para fomentar a noção de ofício e refletir acerca da experiência revelada pelos estagiários no antes. Isto é, oriundas das práticas artísticas e culturais desenvolvidas ao longo do curso de graduação e fora dele, na história de vida, e aquelas que se estabelecem no momento da realização do estágio.

É importante atrelar o professor reflexivo à noção de professor investigativo. Isto é, capaz de sair dos círculos da repetição dos fatos cotidianos para poder 
pensar soluções. Não basta somente identificar os conflitos, mas pensar em soluções possíveis e exequíveis de serem realizadas no contexto, no qual o aluno ou aluna se encontram envolvidos.

Noutro relato de aluno observamos:

[...] Fico sempre com a impressão de que quando falo sobre jogos teatrais e aquecimentos que envolvem organização do coletivo, as pessoas associam a "dinâmicas de grupo" da forma mais pejorativa possivel. Parece que entendem que são exercicios interativos sem nenhuma organização ou objetivos pedagógicos concretos. (relato aluno II).

Reconhecer a fragilidade do ensino de teatro na escola. Refletir e ultrapassar os medos e enfrentar os preconceitos associados ao ensino de teatro na escola é a primeira etapa. É, bem por isso, necessária a consciência histórica relacionada com o ensino de teatro no Brasil e seus desdobramentos atuais.

Noutro relato temos:

[...] percebo que o professor está num lugar bastante movediç, este que é escola. Entre erros e acertos ele vai se desenvolvendo a cada dia, se recriando a cada novo encontro com os alunos e encontrando seus espaços dentro desse espaço maior que é a escola. É preciso destemor, ousadia e sensibilidade para encarar cada dia na escola como um novo dia de descobertas, invenções e renovacõos. Como? (relato aluno III)

Os questionamentos e a incerteza conferem ao processo um caráter emancipatório.

Penso agora, que, meu discurso, que se repete de uma forma incansável, precisa ser dia a dia problematizado, para respirar e encontrar canais para ser expresso, sem que seja embotado por ele mesmo. É preciso encontrar o lugar da criação na escola, independente da estética escolbida. É essencial relacionar-se com a diferença. É preciso vivenciar o teatro nas aulas de Teatro. É preciso que os corpos se expressem. Ee é essencial não acimentar o desejo. Work in progress! (relato aluno VI).

Desse cruzamento de vivências e relatos, se organiza o modo de abordagem e as percepções acerca do território escolar, não com o intuito de repeti-las ou consolidá-las, mas compreendê-las como um vetor de possibilidade de atuação na sala de aula. Entendida como um espaço vivo, dinâmico e permeado de contradições. 
Nesse sentido, deseja-se romper com a lógica, muitas vezes estratificada dos discursos acerca dos insucessos do ensino de teatro na escola, tais como: isso funciona, isso não funciona, da minha sala, eu faço eu resolvo, ou do saber fazer consolidado.

Isso não significa que os problemas não existam e que, em muitos casos, eles não sejam crônicos. A abordagem proposta é considerar o problema do ensino de teatro na escola como algo que se pode ter uma resposta; não se encontra naturalizado na dinâmica docente ou ao qual se acostuma e se segue reclamando. Isto é, segundo Milton Santos em palestra proferida em 2009, na ocasião da discussão do cidadão do Mundo: "em nosso trabalho devemos aprender a recusa do fácil."

O professor de teatro contemporâneo tem sido muitas vezes expresso como professor-artista, artista-professor, docente-artista, artista-docente, entre outras denominações. No discurso enunciativo desses sujeitos, encontramos o desejo de um professor (e a prática pedagógica) em diálogo com a experiência individual artística de cada aluno (mesmo considerando as diferenças pontuais entre cada uma delas).

Os conjuntos/conceitos das definições postulam que a vivência artística pode e deve interferir e/ou contaminar a atividade docente na sala de aula. Revelam a intencionalidade de não separar as práticas artísticas e pedagógicas.

Independente de tais denominações, importa-nos que o licenciado seja capaz de ensinar teatro no contexto curricular da educação básica. É, bem por isso, necessário estar atento aos vários fatores que envolvem a relação, tais como: professor supervisor-aluno; aluno-campo de estágio e supervisor de campo e aluno, entre outros. Pois, como afirma Oliveira e Serrazina (2002, p. 39):

A capacidade de reflectir é também afectada pelos constrangimentos da situação (por exemplo, o peso do trabalho ou a pressão para a inovação), pelas limitações pessoais (por exemplo, nível de desenvolvimento ou de conhecimento) e bem-estar emocional (por exemplo, autoconfiança, autoestima, resposta a críticas negativas) $[\ldots]$.

Assim, o estágio curricular é um espaço permeado por subjetividades que não somente envolvem o trabalho docente e sua condição, mas, também, 
os significados de ser professor e mestre. Deve funcionar como um espaço do fomento da autonomia do sujeito.

É fundamental não deixar de apontar que os processos e as práticas relacionadas à formação teatral na escola ou fora dela, encontram-se ligados à constituição do território e imaginário do Teatro na sociedade.

\section{APONTAMENTOS FINAIS}

O estágio curricular é o espaço no qual os alunos (em formação) revelam as suas potencialidades e, também, as falhas no processo de formação. Nele, o futuro professor poderá observar, discutir, propor e vivenciar um conjunto de atividades e, fundamentalmente, desenvolver a autonomia como docente. Em primeiro lugar, na sala de aula. Espaço organizado, delimitado e coletivo com dinâmicas próprias. É preciso compreendê-lo como o espaço vivo a ser usado e vivenciado, e não um depósito de alunos e professores. Em segundo lugar, o estágio permite ao aluno compreender os espaços fora da sala de aula como espaços possíveis de serem ocupados pela atividade teatral, tais como: cursos ou oficinas regulares, ações de intervenção intencionalmente organizadas e sistematizadas, com assuntos e temas flexíveis e variados. Porém, não como conteúdo à parte. É necessário integrar as atividades que ocorrem no interior e no exterior da sala de aula, para não correr o risco de a ação externa se transformar num projeto pontual, à parte da sala de aula, sem vínculo com a formação contínua do estudante.

Em terceiro lugar, compreender o teatro como conhecimento específico e em sintonia com os desafios contemporâneos da sociedade atual. Para Koudela e Santana (2005, p. 153):

A Pedagogia do Teatro tem como referência teorias contemporâneas de estudos críticos-culturais como o desconstrutivismo, o feminismo e o pós-modernismo. Nesse tipo de teatro, educadores e alunos empregam convenções que desafiam, resistem e desmantelam sistemas de privilégio criados pelos discursos dominantes e práticas discursivas da moderna cultura do ocidente. Dessa forma, a prática da ação dramática cria espaços e possibilidades para dar forma à consciência pós-moderna e pós-colonial, sensíveis à pluralidade, diversidade, inclusão e justiça social.

O estágio funciona, a nosso ver, como um modo de vivenciar e refletir acerca do nosso tempo e, também, discutir os processos de formação e o 
ofício docente. Isto é, espaço de diálogo entre o imaginário teatral esboçado na formação curricular da licenciatura e as práticas teatrais contemporâneas vivenciadas por eles.

Por isso se defende a proposta de que, durante o estágio, se realizem projetos de intervenções teatrais, os quais seriam responsáveis, também, por manter vivos os vínculos da atividade artística - teatro - e, consequentemente, a torná-la visível ao conjunto da sociedade. Mesmo considerando que o objetivo do ensino de teatro na escola não seja o de reproduzir os modelos artísticos da profissão teatro, eles terminam por se embrenhar. Pois o aluno estimulado positivamente na sala de aula pode ser convidado a frequentar o teatro fora da escola.

Assim, no período de estágio, a ser desenvolvido pelos futuros professores, devemos sempre solicitar a realização de projetos que busquem naturalizar a presença do teatro na escola. No sentido de retirar o estranhamento ou a noção de atividade eventual que o teatro possa ter na escola. O teatro presente cotidianamente na escola favorece a sua inserção e diálogo com todas as instâncias da escola.

Por fim, se o teatro e a escola brasileira iniciaram seus caminhos juntos e depois se afastaram, podemos (e devemos) buscar retomar este processo de integração histórico. Nesse sentido, a experiência das atividades dos licenciados no estágio curricular é um espaço privilegiado da observação do futuro professor. É nele que podemos observar os acertos e o descompasso entre o imaginário do aluno, a proposta curricular, o ambiente escolar e, quem sabe, torná-lo um agente da visibilidade do teatro na sociedade. 


\section{REFERÊNCIAS}

ABIRACHED, R. Le théâtre dans la cite: dernières remarques avant une rupture annoncée. Comunications: theaters d'aujourd'hui, Seuil, v. 83, n. 83, p. 25-36, 2008.

BARBOSA, A. M. Arte-educação no Brasil. São Paulo: Perspectiva, 1978.

BOTELHO, I. Romance de formação: Funarte e política cultural 1976-1990. Rio de Janeiro: Casa de Rui Barbosa, 2002.

CALABRE, L. Política cultural no Brasil: um histórico. In: CALABRE, L. (Org.). Política culturais: diálogo indispensável. Rio de Janeiro: Casa de Rui Barbosa, 2005. p. 9-20.

CASTELLS, M. La ciudad de la nueva economía. La Factoría, n. 12, set. 2000. Disponível em: <www.lafactoria.web.com/articulos/castells12.htm>. Acesso em: 12 ago. 2011.

CONSELHO NACIONAL DE EDUCAÇÃO - CNE. Resolução CNE/CP n 1, de 18 de fevereiro de 2002. Institui Diretrizes Curriculares para a Formação de Professores da Educação Básica, em nível superior, curso de licenciatura, de graduação plena. Diário Ofial da República Federativa do Brasil, Brasília, DF, fev. 2002.

FERREIRA JUNIOR, A.; BITTAR, M. Pluralidade lingüística, escola de bê-á-bá e teatro jesuítico no Brasil do século XVI. Educação e Sociedade, São Paulo, v. 25, n. 86, p. 171-195, 2004. http:/ /dx.doi.org/10.1590/S0101-73302004000100009

GALANTE DE SOUZA, J. O Teatro do Brasil. Rio de Janeiro: Instituto Nacional do Livro, 1960

KOUDELA, I. D. Jogos Teatrais. São Paulo: Perspectiva, 1984.

KOUDELA, I.; SANTANA, A. P. Abordagens metodológicas do teatro na educação. Ciências Humanas em Revista, São Luis, v. 3, n. 2, 2005.

LEITE, S. S. J. História da companhia de Jesus no Brasil. Rio de Janeiro: Civilização Brasileira, t. II, 1938.

LUDKE, M.; BOING, L. A. Caminhos da profissão e da profissionalidade docente. Educação e Sociedade, Campinas, v. 25, n. 89, p. 1159-1180, 2004. Disponível em: <http:// www.cedes.unicamp.br>. Acesso em: 24 ago. 2011.

SANTANA, A. P. Teatro e formação de professores. São Luis: EdUFMA, 2000.

SANTANA, A. P. Trajetória, avanços e desafios do teatro-educação no Brasil. Revista Sala Preta, São Paulo, n. 2, p. 247-252, 2002.

TARDIF, M. Saberes docentes e formação profissional. Petrópolis: Vozes, 2002.

MEIRIEU, P. Le thêàtre et l'école: éléments pour une histoire, repères pour avenir. In: LALLIAS, J.-C.; LASSALLE, J.; LORIOL, J.-P. Théâtre et l'école: histoire et perspectives d'une relation passionnée. Paris: Actes Sud, 2002.

SOUSA NETO, M. F. O oficio, a oficina e a profissão: reflexões sobre o lugar social do professor. Cadernos Cedes, Campinas, v. 25, n. 66, p. 249-259, maio/ago. 2005. Disponível em: <http://www.cedes.unicamp.br>.

NÓVOA, A. Para uma formacion de profesores construída dentro de la profession. Revista de Educación, Madrid, n. 350, p. 203-218, set./dez. 2009.

OLIVEIRA, I.; SERRAZINA, L. A reflexão e professor como investigador. In: GRUPO DE TRABALHO DE INVESTIGAÇÃO - GTI (Org.). Reflectir e Investigar sobre a prática 
profissional. Lisboa: APM, 2002. p. 29-42. Disponível em: <http://apm.pt/files/127552_ gti2002_art_pp29-42_49c770d5d8245.pdf>. Acesso em: 04 ago. 2011.

PUPO, M. L. Sinais de teatro-escola. Humanidades, Brasília, n. 52, p. 109-115, nov. 2006. Edição Especial Teatro Pós-Dramático.

PUPO, M. L. Para desembaraçar os fios. Educação e Realidade, Porto Alegre, v. 30, n. 2, p. 217-228, 2005.

SOBRE o Moodle [online]. Disponível em: <http://docs.moodle.org/pt/Sobre_o_moodle>. Acesso em: 29 jun. 2007.

VIGOTSKY, L. S. A Imaginação e a Arte na Infância. Tradução de Voobrajenie i tvorchestvo por Miguel Serras Pereira. Lisboa: Relógio d’Água Editores, 2009. 128 p.

VIGOTSKY, L. S. Psicologia pedagógica. Tradução de Psicología pedagógica: um curso breve. Porto Alegre : Ar'Tmed, 2003. 311 p. (Biblioteca ArTmed. Ciência cognitiva).

YÚDICE, G. A conveniência da cultura: usos da cultura na era global. Belo Horizonte: UFMG, 2004.

\section{NOTAS}

${ }^{1}$ Segundo Maria Lúcia Pupo (2006, p. 109), “[...] quando falamos em pedagogia teatral estamos nos referindo a uma reflexão sobre as finalidades, as condições, os métodos e os procedimentos relativos a processos de ensino/aprendizagem em teatro [...]”.

${ }^{2}$ Ver LDB 9394/96.

${ }^{3}$ Ver, por exemplo, a proposta da Secretaria de Educação do Estado de São Paulo, páginas 55 e 56. Disponível em <http:/ /www.rededosaber.sp.gov.br/portais/Portals/18/arquivos/ Prop_ART_COMP_red_md_15_01_2010.pdf>. A mesma questão pode ser observada noutros documentos de outros estados da federação.

${ }^{4} \mathrm{O}$ termo mediação tem muitas acepções e interpretações na atualidade. Neste artigo, o conceito tem sua fundamentação em Vigotsky (2003, 2009).

${ }^{5}$ Como se pode observar no Ratio Studiorium, elaborado pela Companhia de Jesus no final do século XVI.

${ }^{6}$ Ver ALMEIDA PRADO, D. Teatro de Anchieta e Alencar. São Paulo: Editora Perspectiva, 1993. $346 \mathrm{p}$.

${ }^{7}$ Ver BENEDETTI, J. Stanislavski et les studios. Alternatives Théâtrales, n. 87, p. 4-8, 2007.

${ }^{8}$ Segundo Galante de Souza, o teatro não teria a sua origem com a colonização.

Seria erro, porém, supor que, antes dos jesuítas, não tivesse havido teatro no Brasil. É certo que, antes do teatro missionário, já se promoviam representações teatrais. A prova disso é o fato de ter sido o Auto de Pregação Universal, de Anchieta, composto e representado, a fim de impedir abusos que se cometiam com as representações feitas nas igrejas [...] (SOUZA, 1960, p. 85). 
9 Segundo Ludke e Boind (2004), a "profissão" docente exibe, mesmo aos olhos do observador comum, sinais evidentes de precarização, visíveis pela simples comparação com datas passadas. À parte a nostalgia, que em geral valoriza mais o que já passou ("a minha escola", "a minha professora”...), não é difícil constatar a perda de prestígio, de poder aquisitivo, de condições de vida e, sobretudo de respeito e satisfação no exercício do magistério hoje.

${ }^{10}$ Há poucas escolas nas quais se encontra a disciplina denominada Teatro no currículo da escola. Geralmente são escolas privadas.

${ }^{11}$ Tal condicional é vivenciada nas escolas. Mesmo que os Parâmetros Curriculares Nacionais (PCNs) indiquem para a presença dos conteúdos de Artes Visuais, Dança, Música e Teatro, no dia a dia de muitas escolas, isso não ocorre.

$12 \mathrm{O}$ teatro necessita de um espaço físico diferenciado (da sala de aula com cadeiras) para ser realizado. Requer: piso adequado aos movimentos corporais; revestimento acústico que permita a realização de atividades "barulhentas", de modo que não interfiram nas outras aulas; ventilação adequada à realização de atividades corporais em locais fechados; instalação elétrica que permita a utilização de pequenos refletores ou outros efeitos de iluminação; um local para armazenar os materiais cênicos (figurinos e adereços); sala com possibilidade de escurecimento e equipamento de sonorização.

13 Os relatos dos alunos são postados semanalmente no moodle (SOBRE..., 2007), como parte da estratégia de acompanhamento das atividades realizadas pelos alunos e alunas no estágio supervisionado obrigatório.

Recebido: 04/10/2011 